\title{
Metabolic myopathy due to lactate transporter defect
}

INSERM

\section{Source}

INSERM. (1999). Orphanet: an online rare disease and orphan drug data base. Metabolic myopathy due to lactate transporter defect. ORPHA:171690

Metabolic myopathy due to lactate transporter defect is a rare metabolic myopathy characterized by muscle cramping and/or stiffness after exercise (especially during heat exposure), post-exertional rhabdomyolysis and myog lobinuria, and elevation of serum creatine kinase. 